Research Article

\title{
The complete mitochondrial genome sequence of the little egret (Egretta garzetta)
}

\author{
Yi Zou, Mei-dong Jing, Xiao-xin Bi, Ting Zhang and Ling Huang \\ College of Life Sciences, Ludong University, Yantai, Shandong, P.R. China.
}

\begin{abstract}
Many phylogenetic questions in the Ciconiiformes remain unresolved and complete mitogenome data are urgently needed for further molecular investigation. In this work, we determined the complete mitogenome sequence of the little egret (Egretta garzetta). The genome was 17,361 bp in length and the gene organization was typical of other avian mtDNA. In protein-coding genes (PCGs), a C insertion was found in ND3, and COIII and ND4 terminated with incomplete stop codons (T). tRNA-Val and tRNA-Ser (AGY) were unable to fold into canonical cloverleaf secondary structures because they had lost the DHU arms. Long repetitive sequences consisting of five types of tandem repeats were found at the 3' end of Domain III in the control region. A phylogenetic analysis of 11 species of Ciconiiformes was done using complete mitogenome data and 12 PCGs. The tree topologies obtained with these two strategies were identical, which strongly confirmed the monophyly of Ardeidae, Threskiorothidae and Ciconiidae. The phylogenetic analysis also revealed that Egretta was more closely related to Ardea than to Nycticorax in the Ardeidae, and Platalea was more closely related to Threskiornis than to Nipponia in the Threskiornithidae. These findings contribute to our understanding of the phylogenetic relationships of Ciconiiformes based on complete mitogenome data.
\end{abstract}

Keywords: Egretta garzetta, mitochondrial genome, phylogenomics.

Received: July 4, 2014; Accepted: December 2, 2014.

\section{Introduction}

With more than 9,000 living species, Aves is the most diverse class of vertebrates. The huge number of species, complex morphological characters and wide range of ecological behaviors make it difficult to solve the phylogenetic relationship of birds in traditional taxonomy (Bock, 1956; Howard and Moore, 1980; Monroe and Sibley, 1993).

The order Ciconiiformes, consisting of more than 110 species of large or medium size waders, has traditionally be classified into five families (Ciconiidae, Threskiornithidae, Ardeidae, Balaenicipitidae and Scopidae) (Howard and Moore, 1980; Austin, 1985; Gill, 1990; Clements, 2000; Zheng, 2002). However, there have been various uncertainties regarding the evolutionary relationships of different taxa in this order: (1) The phylogenetic relationships among the five families have been questioned in morphological studies (Kahl, 1972; Cracraft, 1981), (2) the Family Ardeidae was divided into two subfamilies (Ardeinae and Botaurinae) by Bock (1956) and Zheng (1997), but into four subfamilies (Ardeinae, Nycticoracinae, Botaurinae and Tigrisomatinae) by Payne and Risley (1976), and (3) the phylogenetic status of several species in the traditional

Send correspondence to Ling Huang. College of Life Sciences, Ludong University, 264025 Yantai, Shandong, China. E-mail: huangdl@126.com. classification of the subfamily Ardeinae has been questioned. For example, the great egret was initially placed in an independent genus Casmerodius (Peter, 1931), but was put in Egretta by Bock (1956) and Ardea by Payne and Risley (1976). Similarly, the intermediate egret was initially included in Egretta, but then placed in Mesophoyx by Sibley and Monroe (1990). The taxonomic position of the cattle egret had also changed many times; in early taxonomic literature this species belonged to Bubulcus (Peter, 1931), but was subsequently placed in Ardeola by Bock (1956) and in Egretta by Payne and Risley (1976).

Genome sequences, which provide direct information on evolutionary history, are perfect markers for phylogenetic studies since the resulting analyses can be used to assess and revise the conclusions of traditional taxonomy. In the last 30 years, molecular investigations have shed new light on the evolutionary history of the Ciconiiformes. Based on DNA hybridization results, Sibley et al. (1988) merged Ciconiiformes and four other orders (Gaviiformes, Podicipediformes, Lariformes and Charadriiformes) into a huge new order. However, recent molecular studies have proposed the paraphyly of Ciconiiformes because the herons and ibises in this group showed a close relationship with Pelecaniformes, whereas the storks were closely related to Sphenisciformes (Hedges and Sibley, 1994; Cracraft et al., 2004; Hackett et al., 2008; Pacheco et al., 
2011). The North American Classification Committee (NACC) has recommended that the families Ardeidae, Threskiornithidae, Balaenicipitidae and Scopidae be merged into Pelecaniformes, and Ciconiiformes was restricted to include only the Ciconiidae.

Molecular studies of the Ardeidae have indicated that day herons and night herons are closely related, and that Nycticoracinae should be merged into Ardeinae, while the tiger herons and boat-billed heron were basal lineages and should be placed in the Tigrisomatinae and Cochleariinae, respectively (Sheldon, 1987; Sheldon and Kinnarney, 1993; Sheldon et al., 1995, 2000). This four-subfamily classification (Ardeinae, Botaurinae, Tigrisomatinae and Cochleariinae) has been generally accepted. Molecular investigations of the subfamily Ardeinae have shown that the great egret and intermediate egret form a monophyletic lineage that is more closely related to Ardea than to Egretta, indicating that they should not be placed in Egretta (Sheldon, 1987; Sibley and Monroe, 1990; Sheldon and Kinnarney, 1993; Sheldon et al., 1995, 2000; Chang et al., 2003).

In molecular systematics, the topologies of phylogenetic trees vary with the molecular markers used and the number of taxa involved (Zwickl and Hillis, 2002). Consequently, some phylogenetic uncertainties in the Ardeinae (such as the evolutionary status of the cattle egrets Ardeola and Butorides) have not been resolved (Chang et al., 2003; Zhou XP, 2008, PhD thesis, Xiamen University, China).

Mitochondrial DNA (mtDNA), with its intrinsic characteristics (small genome size, simple genome structure, exclusively maternal inheritance, lack of extensive recombination and rapid rate of evolution), has been extensively used in taxonomic and phylogenetic studies of vertebrates (Ingman et al., 2000; Sheldon et al., 2000; Gentile et al., 2009; Zhang and Wake, 2009; Pacheco et al., 2011; Suzuki et al., 2013). Compared to individual genes, complete mitogenomes contain more information on an organisms or taxon's evolutionary history, reduce stochastic errors and minimize the effect of homoplasy in phylogenetic studies (Campbell and Lapointe, 2011). Phylogenies based on complete mitogenomes are generally consistent with those derived from nuclear genes if appropriate sampling of taxa and analysis are applied (Arnason et al., 2002; Reyes et al., 2004; Kjer and Honeycut, 2007). Complete mitogenomes have increasingly been used to address the evolution and radiation of birds (Moum et al., 1994; Sato et al., 1999; Pacheco et al., 2011). To date, more than 260 avian mitogenomes have been deposited in GenBank, only four of which involve species belonging to the Ardeidae (Egretta eulophotes, Ardea novaehollandiae, Ixobrychus cinnamomeus and Nycticorax nycticora). The lack of complete mitogenome data is an important limitation in solving the evolutionary puzzles of the Ardeidae and Ciconiiformes.

In this report, we describe the complete mitogenome sequence of the little egret (Egretta garzetta) and provide a comprehensive analysis of its genome characters. Although the phylogenetic status of this species has been welldefined by morphological and molecular studies (Bock, 1956; Payne and Risley, 1976; McCracken and Sheldon, 1997; Rabosky and Matute, 2013), the availability of its complete mitogenome data will provide useful information for molecular phylogenetic studies and conservation biology of the Ardeidae.

\section{Material and Methods}

\section{Sample collection and extraction of genomic DNA}

One specimen of E. garzetta was collected from Wuyi Mountain, Fujian Province, China. The specimen was identified based on external characteristics, using the system of Sibley and Monroe (1990). Total genomic DNA was extracted from muscle tissue with a Wizard Genomic DNA purification kit (Promega, Madison, WI, USA) according to the manufacturer's instructions. The concentration of extracted DNA was determined using a spectrophotometer and adjusted to $50 \mathrm{ng} / \mu \mathrm{L}$.

\section{PCR amplification and sequencing}

The $E$. garzetta mtDNA was obtained by polymerase chain reactions (PCR) using 28 primer sets reported by Sorenson et al. (1999). The PCR products for each set of primers were $<1,500 \mathrm{bp}$ in size and all fragment sequences overlapped each other by at least $200 \mathrm{bp}$. PCR amplifications were done with a Mycycler Gradient thermocycler (Bio-Rad) in a final volume of $50 \mu \mathrm{L}$, including $5 \mu \mathrm{L}$ of $10 \mathrm{x}$ ${ }^{\mathrm{EX}} \mathrm{Taq}$ buffer $\left(\mathrm{Mg}^{2+}\right.$-free; Takara Biotech, Dalian, China), $2.5 \mathrm{mM}$ of each dNTP, $75 \mathrm{mM} \mathrm{MgCl}, 10 \mu \mathrm{M}$ of each primer, $1.5 \mathrm{U}$ of ${ }^{\mathrm{EX}} \mathrm{Taq}$ polymerase (Takara of Biotech, Dalian, China) and approximately 20-50 ng of total genomic DNA. The reaction included an initial denaturation at $94{ }^{\circ} \mathrm{C}$ for $3 \mathrm{~min}$, followed by 35 cycles consisting of denaturation at $94{ }^{\circ} \mathrm{C}$ for $10 \mathrm{~s}$, annealing at $50-56^{\circ} \mathrm{C}$ for $30 \mathrm{~s}$ and extension at $72{ }^{\circ} \mathrm{C}$ for $2 \mathrm{~min}$, with a final extension at $72^{\circ} \mathrm{C}$ for $10 \mathrm{~min}$. There was a negative control in each round of PCR to check for contamination. The products were electrophoresed on $1.5 \%$ agarose gels staining with ethidium bromide and visualized by ultraviolet transillumination. The PCR products were purified with a gel extraction kit (Sangon BioMedical, Shanghai, China) and directly sequenced (both directions) with an ABI 3730XL automatic sequencer (Perkin-Elmer) using an ABI PRISM BigDye Terminator Cycle Sequencing Ready Reaction kit (with AmpliTaq DNA polymerase FS, Applied Biosystems).

\section{Sequence assembly, annotation and analysis}

Sequence assembly and annotation were done using the DNASTAR software package (Lasergene version 5.0; Madison, WI, USA). The boundaries of protein-coding genes and rRNA genes were determined by aligning our sequences with the complete mtDNA sequences of $A$. 
novaehollandiae (NC_008551) and Gallus gallus (NC_001323; Galliformes: Phasianidae) in GenBank. The boundaries and the cloverleaf secondary structures of tRNAs were identified by tRNAscan-SE v 1.12 with the default settings. The complete nucleotide sequence was submitted to GenBank under accession no. NC_023981 and the blast sequences are submitted to DRYAD (doi:10.5061/dryad.3g604). The base composition for protein-coding genes (PCGs), the codon usage of 13 PCGs and the pairwise distances among mitogenomes of the species studied were calculated with MEGA version 5 (Tamura et al., 2011).

\section{Phylogenetic inference using mitogenomes}

The phylogenetic relationships among E. garzetta and four other species in the Ardeidae (A. novaehollandiae, E. eulophotes, I. cinnamomeus and N. nycticorax), four species in the Threskiornithidae (Platalea leucorodia, Platalea minor, Threskiornis aethiopicus and Nipponia nippon) and two species in the Ciconiidae (Ciconia boyciana, Ciconia ciconia) were constructed with complete mtDNA sequences and 12 PCGs (excluding ND6). Two species in the family Anatidae, order Anseriformes (Branta canadensis, NC_007011; Anas platyrhynchos, EU009397) were designated as outgroups. The relevant information for each genome is presented in Table $\mathrm{S} 1$.

The program Modeltest version 3.7 (Posada and Crandall, 1998) was used to choose an appropriate substitution model of sequence evolution. The GTR $+\mathrm{I}+\mathrm{G}$ model was selected as the best fitting model. For the Bayesian procedure, four independent Markov chains were run for $10,000,000$ generations by sampling one tree per 1,000 generations and allowing adequate time for convergence. After discarding the first 2,500 trees (25\%) as part of a burn-in procedure that was determined by checking for the likelihood of being stationary, we used the remaining 7,500 sampling trees to construct a $50 \%$ majority rule consensus tree. Two independent runs were used to provide additional confirmation of the convergence of the Bayesian posterior probabilities (BPP) distribution.

\section{Results and Discussion}

\section{Genome organization and base composition}

The complete mitogenome of E. garzetta is a circular molecule 17,361 bp in length (Figure 1). This size is intermediate to all available ardeid mitogenomes, which range from 17,180 bp (I. cinnamomeus; Zhang et al., 2012) to 17,829 bp (N. nycticorax, NC_015807). The gene organization is identical to that of typical avian mtDNA (Wolstenholme, 1992; Boore, 1999; Roques et al., 2004; Gibb et al., 2007; Kan et al., 2010; Zhang, et al., 2012; Figure 1). Table 1 shows the various features of this genome. There are six regions in which genes overlapped by $29 \mathrm{bp}$ and 18 intergenic spacer regions comprising a total of $97 \mathrm{bp}$.

The base composition of the E. garzetta mitogenome revealed a slight bias towards $\mathrm{A}+\mathrm{T}(31.5 \% \mathrm{~A}, 23.2 \% \mathrm{~T}$, $31.8 \% \mathrm{C}$ and $13.5 \% \mathrm{G})$. The $\mathrm{A}+\mathrm{T}$ content for the whole $\mathrm{H}$-strand, different genes and control regions was estimated for 11 mitogenomes in Ciconiiformes (Table 2). This analysis showed that, except for the first codon of PCGs, other portions of these mitogenomes showed varying degrees of preference for $\mathrm{A} / \mathrm{T}$. The equations $\mathrm{AT}$-SKEW= $(\mathrm{A}-\mathrm{T}) /(\mathrm{A}+\mathrm{T})$ and $\mathrm{GC}-\mathrm{SKEW}=(\mathrm{G}-\mathrm{C}) /(\mathrm{G}+\mathrm{C})$ can be used to calculate the skew for a given strand to investigate nucleotide bias (Perna and Kocher, 1995). The positive AT-skew (0.138) and negative GC-skew (-0.399) for the E. garzetta mitogenome suggested the occurrence of more $\mathrm{A}$ and $\mathrm{C}$ than $\mathrm{T}$ and $\mathrm{G}$, which is consistent with other avian mitogenomes (Haring et al., 2001; Kan et al., 2010; Yang et al., 2010; Zhang et al., 2012).

\section{Protein-coding genes and codon usage}

The total length of 13 PCGs in the E. garzetta mitogenome was $11,225 \mathrm{bp}$, and most of the PCGs were separated by one or more tRNAs (Figure 1). The gene sizes and structures were not significantly different from those of other avian species (Yamamoto et al., 2000; Haring et al., 2001; Yang et al., 2010; Kan et al., 2010; Zhang et al., 2012). There is a $\mathrm{C}$ insertion at position 174 in ND3, and this insertion was also found in some species of Palaeognathae, e.g., NC_002784, NC_002778 and NC_002782 (Härlid et al., 1998) and Neognathae, e.g., NC_011307 and NC_010962 (Zhang et al., 2012). Other analyses have proposed that the insertion is not $\mathrm{C}$ at position 174 but $\mathrm{A}$ at position 175, as reported in the mitogenomes of Otis tarda (Gruiformes: Otididae, NC_014046) (Yang et al., 2010) and Trachemys scripta (Testudoformes: Emydidae) (Russell and Beckenbach, 2008). The function of this extra $\mathrm{C}$ or $\mathrm{A}$ in ND3 and its phylogenetic implications are not well known (Russell and Beckenbach, 2008), but the effect of this insertion on gene expression can be removed by RNA alternative splicing or a frameshift (Mindell et al., 1998).

The average A+T value of 13 PCGs in E. garzetta is $53.10 \%$ (Table 3). Except for ND1, the other PCGs had positive AT-skew $(0.016 \sim 0.563)$ and negative GC-skew (-0.295 -0.733), indicating the occurrence of more A and $\mathrm{C}$ than $\mathrm{T}$ and $\mathrm{G}$ (Table 3 ). The nucleotide compositions of three codons in PCGs were estimated for 11 species (Table 4). The results showed that the smallest and greatest variations occurred in the second (A $0.5 \%, \mathrm{G} 0.3 \%, \mathrm{C}$ $0.6 \%$, T $0.5 \%$ ) and third (A 4.4\%, G 3.0\%, C 5.5\%, T 3.7\%) codons, respectively. The second codon is generally considered to have undergone maximum selective pressure, followed by the first and third codons and other non-coding regions. Different selective pressures result in different nucleotide variability (Zhong et al., 2002). Table 4 also shows that the G content of the third codon (only 4.1\%) was the 


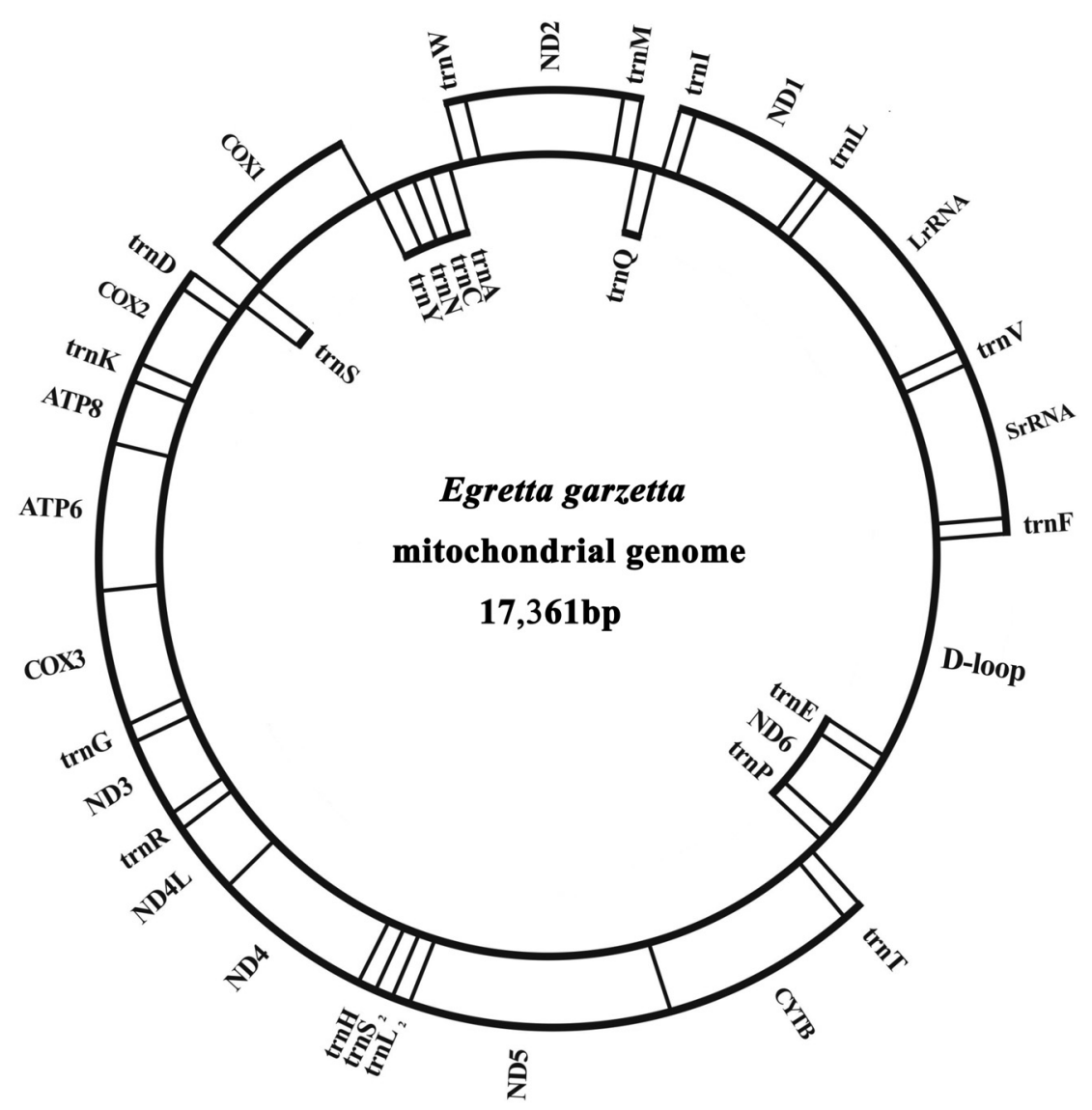

Figure 1 - Gene organization of the E. garzetta mitogenome. ND1-6 refers to NADH dehydrogenase subunits 1-6, COI-III refer to cytochrome c oxidase subunits 1-3, ATP6 and ATP8 refer to ATPase subunits 6 and 8, and $C y t b$ refers to cytochrome b. Twenty-two tRNA genes are designated by single-letter amino acid codes.

smallest of the three codons. A similar phenomenon has also been found in mammalian mitogenomes (Reyes et al., 2004; Gibson et al., 2005).

The start and stop codons for the PCGs of the $E$. garzetta mitogenome are shown in Table 1. COIII and DN4 terminated with an incomplete stop codon $(\mathrm{T})$. The use of an incomplete stop codon (T) is common in avian (Härlid et al., 1998; Haring et al., 2001; Yang et al., 2010; Zhang et al., 2012) and mammalian (Wolstenholme, 1992; Arnason et al., 2002; Gibson et al., 2005; Bi et al., 2012; Chen et al., 2012; Song et al., 2012) mitogenomes, and can form a complete UAA terminal signal by posttranscriptional polyadenylation (Ojala et al., 1981; Boore, 2004).

The ND6 gene was located in the L-strand and its base composition was very different from the other 12 PCGs (Table 3) so it was excluded from the codon usage analysis. Twelve E. garzetta PCGs consisted of 3,626 codons, excluding termination codons (Table S2). The usage frequencies of 21 amino acids ranged from $0.69 \%$ (Cys) to $17.9 \%$ (Leu). Except for Leu, the most frequently used amino acids were Ile (11.47\%), Thr (9.93\%) and Ala (7.73\%), which was similar with those of other ardeid species (Zhang et al., 2012).

\section{Ribosomal and transfer RNA genes}

Animal mitogenomes contain small ( $s r R N A)$ and large (lrRNA) subunits of rRNA (Wu et al., 2003; Gibson et al., 2005; Kan et al., 2010; Krajewski et al., 2010; Bi et al., 2012; Chen et al., 2012; Zhang et al., 2012; Gao et al., 2013), and E. garzetta was no exception (Figure 1). The $\mathrm{A}+\mathrm{T}$ content for $\operatorname{sr} R N A$ and $\operatorname{lr} R N A$ was $50.8 \%$ and $54.7 \%$, respectively, and these values were relatively small among the 11 mitogenomes (Table 2).

Based on the respective anticodons and secondary structures, 22 tRNA genes were identified and their sizes ranged from $67 \mathrm{bp}\left(t R N A^{C y s}\right)$ to $74 \mathrm{bp}\left(t R N A^{\text {Leu }} \mathrm{UUR}\right.$, $t R N A^{A s n}, t R N A^{\mathrm{Ser}} \mathrm{UCN}, t R N A^{\text {Glu }}$ ). Twenty tRNAs can fold into canonical cloverleaf secondary structures, while tRNA-Val and tRNA-Ser (AGY) lost the DHU (dihydrouracil) arms. The cloverleaf structures of tRNA-Val and tRNA-Ser (AGY) were identified by comparing them with counterparts in the E. eulophotes mitogenome (NC_009736). In vertebrate mitogenomes, tRNA-Ser (AGY) generally cannot fold into the canonical cloverleaf secondary structure (Härlid et al., 1998; Shi et al., 2002; Wu et al., 2003; Yang et al., 2010; Gao et al., 2013). Al- 
though the gene sizes and anticodon nucleotides agreed with those described for other vertebrates, there were some atypical pairings in the stem regions, such as A-A, A-C, U-C and U-U wobbles. Generally, the tRNA cloverleaf structure contained $7 \mathrm{bp}$ in the aminoacyl stem, $5 \mathrm{bp}$ in the TYC and anticodon stems, and 4 bp in the D-stem. How- ever, some tRNAs, e.g., tRNA-Phe, tRNA-Leu (CUN) and tRNA-Ile, lacked one or two bp in the T-stem, anticodon stem or D-stem.

\section{Non-coding regions}

The non-coding region (the control region, $\mathrm{mtCR}$ ) of the E. garzetta mitogenome was determined as $1,812 \mathrm{bp}$ in

Table 1 - Organization of the E. garzetta mitochondrial genome.

\begin{tabular}{|c|c|c|c|c|c|c|c|}
\hline \multirow[t]{2}{*}{ Gene } & \multicolumn{2}{|c|}{ Position $^{\mathrm{a}}$} & \multirow[t]{2}{*}{ Size (bp) } & \multirow{2}{*}{$\begin{array}{l}\text { Spacer }(+) / \\
\text { Overlap }(-)\end{array}$} & \multirow[t]{2}{*}{ Strand $^{b}$} & \multicolumn{2}{|c|}{ Codon } \\
\hline & From & To & & & & $\operatorname{Start}^{\mathrm{c}}$ & Stop $^{c}$ \\
\hline tRNA-Phe & 1 & 69 & 69 & 0 & $\mathrm{H}$ & & \\
\hline $12 \mathrm{~s}-\mathrm{rRNA}$ & 70 & 1040 & 971 & 0 & $\mathrm{H}$ & & \\
\hline tRNA-Val & 1041 & 1111 & 71 & 0 & $\mathrm{H}$ & & \\
\hline 16s-rRNA & 1112 & 2718 & 1607 & 0 & $\mathrm{H}$ & & \\
\hline tRNA-Leu (UUR) & 2719 & 2792 & 74 & 8 & $\mathrm{H}$ & & \\
\hline$N D 1$ & 2801 & 3778 & 978 & 7 & $\mathrm{H}$ & ATG & AGA \\
\hline tRNA-Ile & 3786 & 3856 & 71 & 11 & $\mathrm{H}$ & & \\
\hline tRNA-Gln & 3868 & 3937 & 70 & 0 & $\mathrm{~L}$ & & \\
\hline tRNA-Met & 3938 & 4005 & 68 & 0 & $\mathrm{H}$ & & \\
\hline ND2 & 4006 & 5044 & 1039 & 0 & $\mathrm{H}$ & ATG & TAG \\
\hline tRNA-Trp & 5045 & 5116 & 72 & 2 & $\mathrm{H}$ & & \\
\hline tRNA-Ala & 5119 & 5186 & 68 & 10 & $\mathrm{~L}$ & & \\
\hline tRNA-Asn & 5197 & 5270 & 74 & 3 & $\mathrm{~L}$ & & \\
\hline tRNA-Cys & 5274 & 5340 & 67 & -1 & $\mathrm{~L}$ & & \\
\hline tRNA-Tyr & 5340 & 5411 & 72 & 13 & $\mathrm{~L}$ & & \\
\hline COI & 5425 & 6975 & 1551 & -9 & $\mathrm{H}$ & GTG & AGG \\
\hline tRNA-Ser (UCN) & 6967 & 7040 & 74 & 2 & $\mathrm{~L}$ & & \\
\hline tRNA-Asp & 7043 & 7111 & 69 & 1 & $\mathrm{H}$ & & \\
\hline CO II & 7113 & 7796 & 684 & 1 & $\mathrm{H}$ & ATG & TAA \\
\hline tRNA-Lys & 7798 & 7867 & 70 & 1 & $\mathrm{H}$ & & \\
\hline ATP8 & 7869 & 8036 & 168 & -10 & $\mathrm{H}$ & ATG & TAA \\
\hline ATP6 & 8027 & 8710 & 684 & -1 & $\mathrm{H}$ & ATG & TAA \\
\hline CO III & 8710 & 9493 & 784 & 0 & $\mathrm{H}$ & ATG & $\mathrm{T}^{\mathrm{d}}$ \\
\hline tRNA-Gly & 9494 & 9562 & 69 & 0 & $\mathrm{H}$ & & \\
\hline ND3 & 9563 & 9914 & 352 & 2 & $\mathrm{H}$ & ATT & TAA \\
\hline tRNA-Arg & 9917 & 9985 & 69 & 1 & $\mathrm{H}$ & & \\
\hline$N D 4 L$ & 9987 & 10283 & 297 & -7 & $\mathrm{H}$ & ATG & TAA \\
\hline$N D 4$ & 10277 & 11654 & 1378 & 0 & $\mathrm{H}$ & ATG & $\mathrm{T}^{\mathrm{d}}$ \\
\hline tRNA-His & 11655 & 11724 & 70 & 0 & $\mathrm{H}$ & & \\
\hline tRNA-Ser (AGY) & 11725 & 11792 & 68 & -1 & $\mathrm{H}$ & & \\
\hline tRNA-Leu (CUN) & 11792 & 11863 & 72 & 0 & $\mathrm{H}$ & & \\
\hline ND5 & 11864 & 13678 & 1815 & 10 & $\mathrm{H}$ & ATG & AGA \\
\hline$C y t b$ & 13689 & 14831 & 1143 & 3 & $\mathrm{H}$ & ATG & TAA \\
\hline tRNA-Thr & 14835 & 14904 & 70 & 11 & $\mathrm{H}$ & & \\
\hline tRNA-Pro & 14916 & 14987 & 72 & 8 & $\mathrm{~L}$ & & \\
\hline ND6 & 14996 & 15472 & 477 & 3 & $\mathrm{~L}$ & ATG & AGA \\
\hline tRNA-Glu & 15476 & 15549 & 74 & 0 & $\mathrm{~L}$ & & \\
\hline Control region & 15550 & 17361 & 1812 & 0 & $\mathrm{H}$ & & \\
\hline
\end{tabular}

a'Position numbering starts with the 5' position of the Control region; ${ }^{\mathrm{b}} \mathrm{Genes}$ transcribed from the $\mathrm{L}$ or $\mathrm{H}$ strand; ${ }^{\mathrm{c}} \mathrm{Start}$ and stop codons of protein-coding genes; ${ }^{\mathrm{d} P r o t e i n}$-coding genes overlapping with tRNA genes end with an incomplete stop codon. 


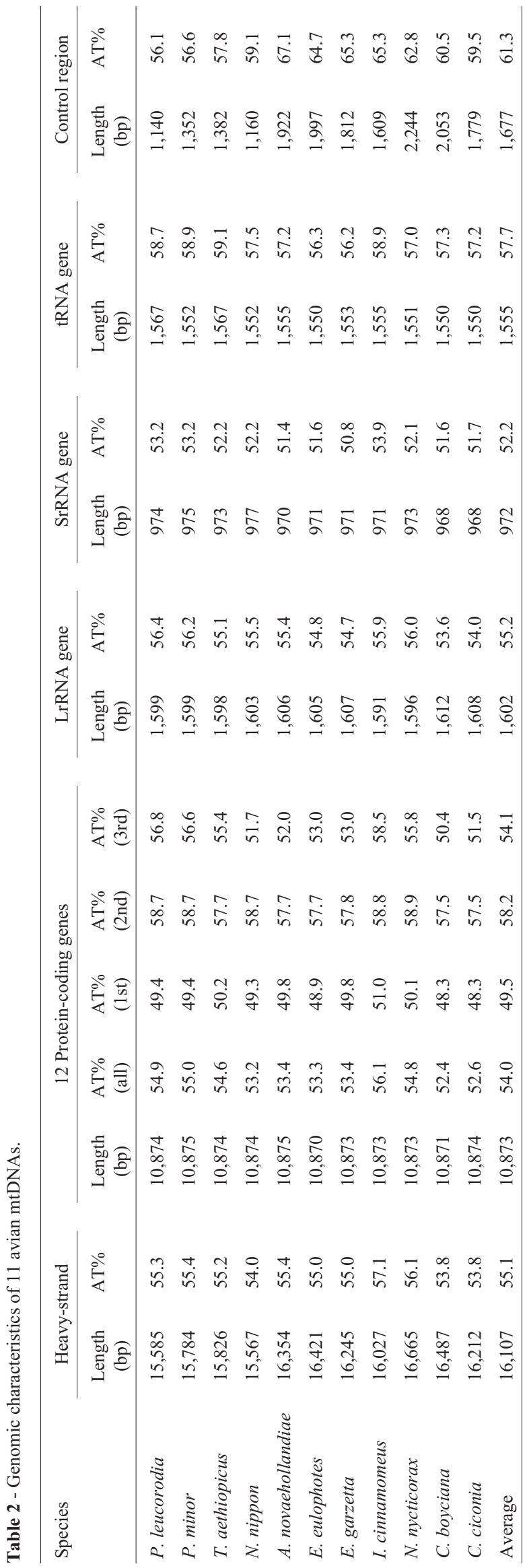

length and located between $t R N A^{G l u}$ and $t R N A^{\text {Phe }}$ (Table 1, Figure 1). The mtCR controls the replication and transcription of animal mitogenomes (Shadel and Clayton, 1997; Taanman, 1999). Based on the nucleotide composition, the mtCR region of E. garzetta contains three domains: a 5'peripheral domain (Domain I), a central conserved domain (Domain II) and a 3'-peripheral domain (Domain III), an organization that was similar to that of other birds (Southern et al., 1988; Saccone et al., 1991; Randi et al., 2000; Roques et al., 2004; Wang et al., 2008; Yang et al., 2010; Zhang et al., 2012; Figure 2).

In Domain I (nt 1-328), two putative extended termination-associated sequence blocks (ETAS1 and ETAS2) were recognized and two putative termination-associated sequences (TAS, conserved palindromic motifs 5'TACAT-3' and 5'-TATAT-3') that act as a signal to terminate synthesis of the control region (Saccone et al., 1991; Randi and Lucchini, 1998; Yamamoto et al., 2000; Haring et al., 2001; Roques et al., 2004) were found in ETAS1. In some birds and mammals, there is a $\mathrm{C}$ structure located close to the 5'-peripheral domain of Domain I that can potentially form a stable goose hairpin structure (Quinn and Wilson, 1993; Douzery and Randi, 1997; Sbisà et al., 1997; Randi and Lucchini, 1998); this structure consists of a stem with seven complementary ' $\mathrm{C}$ 's/' $\mathrm{G}$ 's and a loop containing a TCCC motif (Dufresne et al., 1996; Yang et al., 2010). This structure is speculated to be related to H-strand termination (Dufresne et al., 1996). The hairpin structure cannot be formed in any of the available ardeid mitogenomes because the interrupted poly-C sequences in Domain I of four species (A. novaehollandiae NC_008551, E. eulophotes NC_009736, N. nycticora NC_015807 and E. garzetta NC_023981) are not followed by a G stretch and Domain I of I. cinnamomeus has no poly-C sequence (Zhang et al., 2012). A sequence block similar to the conserved sequence block (CSB1) was found in Domain I (Figure 2) and similar structures have been observed in other avian mitogenomes (Desjardins and Morais, 1990; Quinn and Wilson, 1993; Randi and Lucchini, 1998; Kan et al., 2010; Zhang et al., 2012).

In Domain II (nt 329-794), four conserved sequence boxes (F, E, D and C) were detected (Figure 2) after aligning with reported counterparts in birds and mammals (Walberg and Clayton, 1981; Southern et al., 1988; Desjardins and Morais, 1990; Quinn and Wilson, 1993; Randi and Lucchini, 1998; Roques et al., 2004; Kan et al., 2010; Yang et al., 2010; Zhang et al., 2012).

Domain III (nt 795-1812) comprised a conserved sequence block (CSB-1) that regulates mtDNA replication (Figure 2). A poly(C) sequence located upstream of the CSB1 was assumed to represent the origin of $\mathrm{H}$-strand replication $\left(\mathrm{O}_{\mathrm{H}}\right)$ (Walberg and Clayton, 1981; Figure 2). A poly (T) sequence located downstream of the CSB1 was also observed in the mtCR of other birds (NC_008551, NC_009736; NC_015807; Kan et al., 2010; Zhang et al., 
Table 3 - Base composition for protein-coding genes found in mtDNA of E. garzetta.

\begin{tabular}{lcccccccc}
\hline \multirow{2}{*}{ Gene } & Length $(\mathrm{bp})$ & \multicolumn{9}{c}{ Proportion of nucleotides $(\%)$} & \multicolumn{2}{c}{ AT Skew } & \multirow{2}{*}{ GC Skew } \\
\cline { 3 - 6 } & & $\mathrm{A}$ & $\mathrm{C}$ & $\mathrm{G}$ & $\mathrm{T}$ & $\mathrm{A}+\mathrm{T}$ & & \\
\hline ND1 & 978 & 26.38 & 34.46 & 12.68 & 26.48 & 52.86 & -0.002 & -0.462 \\
ND2 & 1039 & 32.63 & 33.59 & 10.11 & 23.68 & 56.31 & 0.159 & -0.537 \\
COX1 & 1551 & 28.24 & 30.11 & 16.38 & 25.27 & 53.51 & 0.056 & -0.295 \\
COX2 & 684 & 31.43 & 31.43 & 14.18 & 22.95 & 54.38 & 0.156 & -0.378 \\
ATP8 & 168 & 32.14 & 38.69 & 5.95 & 23.21 & 55.35 & 0.161 & -0.733 \\
ATP6 & 684 & 30.12 & 36.84 & 9.94 & 23.10 & 53.22 & 0.132 & -0.575 \\
COX3 & 784 & 28.57 & 31.76 & 15.43 & 24.23 & 52.80 & 0.082 & -0.346 \\
ND3 & 352 & 26.70 & 36.08 & 11.36 & 25.85 & 52.55 & 0.016 & -0.521 \\
ND4L & 297 & 29.97 & 35.35 & 11.45 & 23.23 & 53.20 & 0.127 & -0.511 \\
ND4 & 1378 & 31.49 & 36.21 & 9.65 & 22.64 & 54.13 & 0.163 & -0.579 \\
ND5 & 1815 & 31.90 & 35.43 & 10.85 & 21.82 & 53.72 & 0.188 & -0.531 \\
CYTB & 1143 & 27.47 & 37.10 & 12.60 & 22.83 & 50.30 & 0.092 & -0.493 \\
ND6 & 477 & 37.53 & 41.93 & 10.06 & 10.48 & 48.01 & 0.563 & -0.613 \\
Average & & 30.35 & 35.31 & 11.59 & 22.75 & 53.10 & 0.146 & -0.506 \\
\hline
\end{tabular}

Table 4 - Nucleotide compositon of the 13 protein-coding genes.

\begin{tabular}{|c|c|c|c|c|c|c|c|c|c|c|c|c|}
\hline \multirow[t]{2}{*}{ Species } & \multicolumn{4}{|c|}{$1^{\text {st }}$ codon position } & \multicolumn{4}{|c|}{$2^{\text {nd }}$ codon position } & \multicolumn{4}{|c|}{$3^{\text {rd }}$ codon potion } \\
\hline & $\mathrm{A} \%$ & $\mathrm{G} \%$ & $\mathrm{C} \%$ & $\mathrm{~T} \%$ & $\mathrm{~A} \%$ & $\mathrm{G} \%$ & $\mathrm{C} \%$ & $\mathrm{~T} \%$ & $\mathrm{~A} \%$ & $\mathrm{G} \%$ & $\mathrm{C} \%$ & $\mathrm{~T} \%$ \\
\hline P. leucorodia & 29.7 & 20.2 & 30.0 & 20.1 & 20.1 & 12.3 & 29.3 & 38.3 & 41.4 & 3.8 & 40.4 & 14.4 \\
\hline P. minor & 29.7 & 20.2 & 29.9 & 20.2 & 20.0 & 12.4 & 29.2 & 38.4 & 41.3 & 4.0 & 40.0 & 14.7 \\
\hline T. aethiopicus & 29.5 & 20.4 & 29.7 & 20.3 & 20.0 & 12.4 & 29.6 & 38.0 & 41.0 & 4.1 & 40.8 & 14.1 \\
\hline N. nippon & 29.5 & 20.4 & 30.7 & 19.4 & 20.0 & 12.4 & 29.3 & 38.3 & 39.2 & 5.4 & 43.3 & 12.1 \\
\hline A. novaehollandiae & 30.1 & 20.1 & 30.4 & 19.4 & 20.1 & 12.2 & 29.7 & 38.0 & 40.6 & 3.9 & 44.1 & 11.4 \\
\hline E. eulophotes & 30.3 & 20.0 & 30.6 & 19.1 & 20.0 & 12.4 & 29.7 & 37.9 & 40.6 & 4.0 & 43.9 & 11.5 \\
\hline E. garzetta & 30.0 & 20.1 & 30.5 & 19.4 & 20.1 & 12.2 & 29.7 & 38.0 & 40.5 & 4.0 & 43.7 & 11.8 \\
\hline I. cinnamomeus & 30.8 & 19.4 & 28.8 & 21.0 & 20.1 & 12.3 & 29.4 & 38.2 & 43.2 & 2.4 & 39.6 & 14.8 \\
\hline N. nycticorax & 30.5 & 20.0 & 30.0 & 19.5 & 20.2 & 12.3 & 29.3 & 38.2 & 40.4 & 4.6 & 39.9 & 15.1 \\
\hline C. boyciana & 29.7 & 20.5 & 31.1 & 18.7 & 19.8 & 12.4 & 29.8 & 38.0 & 38.8 & 4.6 & 45.1 & 11.5 \\
\hline C. ciconia & 29.7 & 20.5 & 31.1 & 18.7 & 19.7 & 12.5 & 29.8 & 38.0 & 39.1 & 4.4 & 44.5 & 12.0 \\
\hline Range & 1.3 & 1.1 & 2.3 & 2.3 & 0.5 & 0.3 & 0.6 & 0.5 & 4.4 & 3.0 & 5.5 & 3.7 \\
\hline Average & 30.0 & 20.2 & 30.3 & 19.6 & 20.0 & 12.3 & 29.5 & 38.1 & 40.6 & 4.1 & 42.3 & 13.0 \\
\hline
\end{tabular}

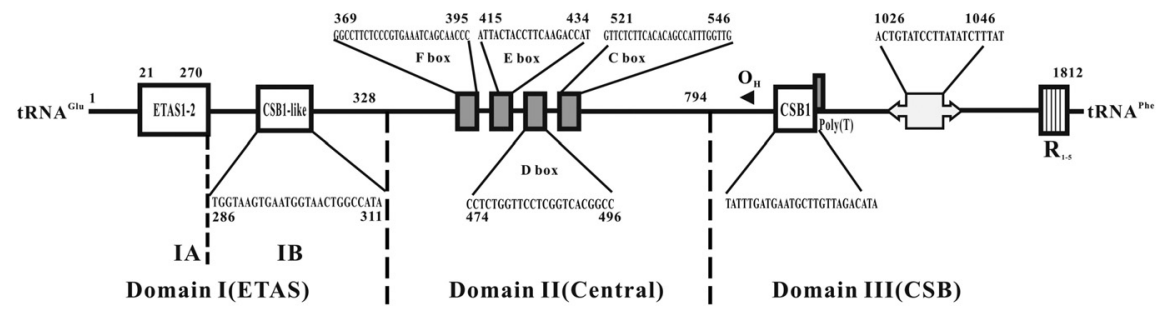

Figure 2 - Schematic representation of the control region in the mitogenome of E. garzetta. The first box represents the extended termination-associated sequences (ETAS1 and ETAS2). Boxes F, E, D and C represent the conserved sequence boxes in the central domain. CSB - conserved sequence block, CSB-like - a sequence similar to CSB, LSP and HSP - light-strand and heavy-strand transcription promoters, respectively, and Rs - tandem repeats in the control region. 
2012). The bidirectional light- and heavy-strand transcription promoters (LSP/HSP) described in other birds (L'abbé et al., 1991; Randi and Lucchini, 1998; Ritchie and Lambert, 2000; Kan et al., 2010; Zhang et al., 2012) also existed in Domain III of E. garzetta. In addition, long tandem repeats were found at the 3 ' end of Domain III and could be divided into two regions: the first region (nt 977 to 1399) contained three types of tandem repeats: 5'TACTTTAAAGCACTAAAA-3' (6x18 bp), 5'TTTCATTAAAAATATACTATACCCTTCATGAAC-3' (5x33 bp), and 5'- TGTATCCTTATATCTTTATGT TACCTTTAC-3' (4x30 bp) while the second region (nt 1406 to 1804) comprised two types of tandem repeats: 5'TAAACAA -3' (26x7 bp) and 5'- CAAACAA -3' (30x7 bp). The existence of repetitive sequences contributed to the large size of the mtCR and the high content of A. Similar tandem repeats (CAAA or CAAACAA) were found in species of Charadriiformes (NC_003712, NC 003713, NC 007978, NC 018548, NC_017601, NC_024069; Wenink et al., 1994) and Gruiformes (Yang et al., 2010), and in C. boyciana in Ciconiiformes (Yamamoto et al., 2000). These repetitive sequences have been speculated to result from the pause of $\mathrm{H}$-strand replication and subsequent slipped mispairing (Fumagalli et al., 1996). The presence of similar conserved repeat sequences in different animal groups (Douzery and Randi, 1997; Nesbø et al., 1998) has led some researchers to propose that these tandem repeats may have an important role in regulating mitogenome replication and transcription (Delarbre et al., 2001; Delport et al., 2002).

\section{Phylogenomic relationships of 11 species in Ciconiiformes}

Mitochondrial sequences provide valuable information for tracing the history of gene rearrangements and phylogenetic reconstructions (Härlid et al., 1998; Braband et al., 2010; Oh et al., 2010; Yang et al., 2010; Cerasale et $a l ., 2012)$. The availability of an increasing number of complete avian mitogenomes has allowed the construction of phylogenetic trees with better resolution, the results of which show better agreement with morphological and nuclear marker studies (Zhang and Wake, 2009; Pacheco et al., 2011). The phylogenetic tree that included E. garzetta and ten other species in Ciconiiformes (Table S1) was constructed using complete mitogenome sequences, with $A$. platyrhynchos (EU009397) and B. canadensis (NC_007011) as outgroups. Since some investigators have preferred to use PCGs in tree construction (Härlid et al., 1998; Gibson et al., 2005; Shen et al., 2009; Zhang et al., 2012), we also ran an analysis with 13 PCGs to assess the congruence between these two strategies. The results showed that although several regions (tRNAs, CR, rRNAs and ND6) presented some problems in the analysis, e.g., difficulties in alignment, numerous gaps, potential saturation and heterogeneous base composition (Gardner et al.,
2005; Sullivan and Joyce, 2005; Krajewski et al., 2010; Oh et al., 2010), the topologies of the phylogenetic trees generated by the two strategies were the same (Figure 3).

The phylogenetic relationships among species/genera within the three families examined here were consistent with the conclusions of previous investigations (Sheldon et al., 2000; Chang et al., 2003; Zhang et al., 2012). The monophyly of the Ardeidae, Threskiorothidae and Ciconiidae was strongly confirmed (posterior probabilities $=1.00$; Figure 3). In the Ardeidae, I. cinnamomeus was the basal clade and Egretta more closely related to Ardea than to Nycticorax. In Threskiornithidae, Platalea was more closely related to Threskiornis than to Nipponia. The relationships revealed by the phylogenetic trees were also supported by the pairwise distances among mitogenomes (Table S3).

With regard to the evolutionary relationships among the three families, our results supported a closer relationship between Threskiorothidae and Ciconiidae than between Threskiorothidae and Ardeidae, a conclusion similar to that based on amino acid data from 12 PCGs (Zhang et al., 2012), but different from that of Hackett et al. (2008) and Pacheco et al. (2011). Since the topologies of molecular phylogenetic trees often vary with the markers and taxa used (Zwickl and Hillis, 2002), divergent evolutionary relationships have often been suggested for the families of

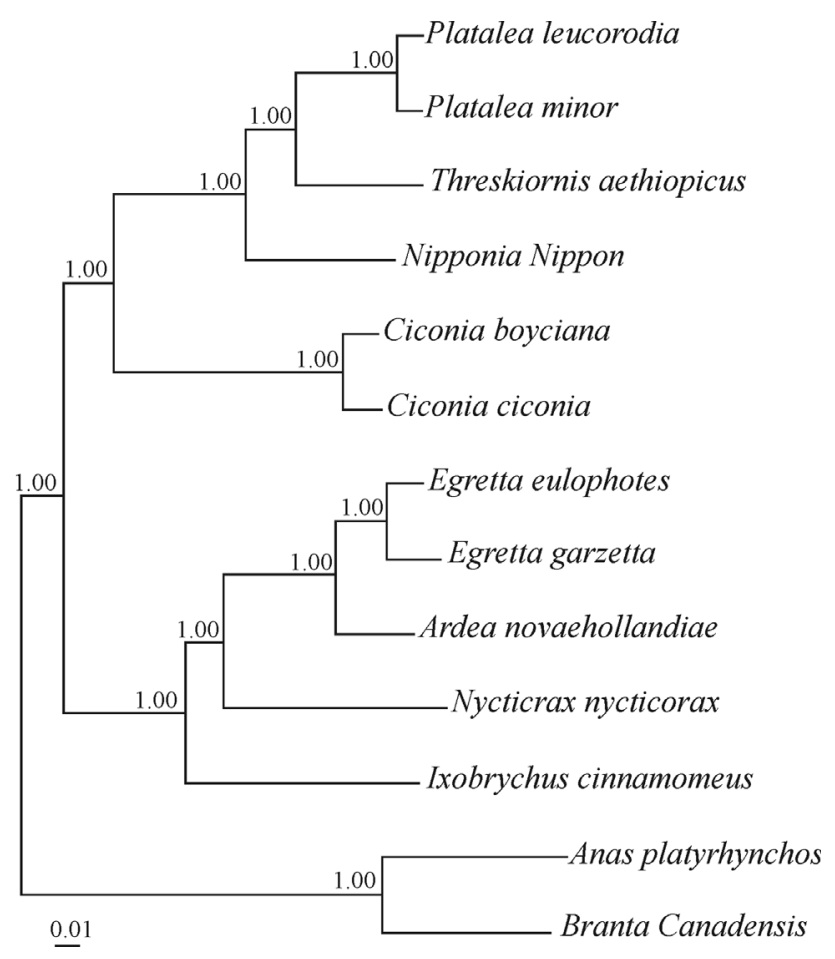

Figure 3 - Bayesian tree based on the complete mitochondrial genome data and 13 PCGs with the GIR $+\mathrm{I}+\mathrm{G}$ model. The horizontal length of each branch corresponds to the substitution rates estimated with the model. Anas platyrhynchos and Branta canadensis were used as outgroups. Numbers on the branches are the bootstrap values for Bayesian posterior probability. 
Ciconiiformes (Gibb et al., 2007; Hackett et al., 2008; Pacheco et al., 2011; Zhang et al., 2012; this study). More complete mitogenome data for the Ardeidae (and other families in Ciconiiformes) are urgently needed for detailed molecular systematic analyses in this order. The mitogenome sequence data presented here represent a contribution to this long-term goal.

\section{Acknowledgments}

This work was supported by the Natural Scientific Foundation of China (grant nos. 31171189 and 31371252).

\section{References}

Arnason U, Adegoke JA, Bodin K, Born EW, Esa YB, Gullberg A, Nilsson M, Short RV, Xu X and Janke A (2002) Mammalian mitogenomic relationships and the root of the eutherian tree. Proc Natl Acad Sci USA 99:8151-8156.

Austin OL (1985) Families of Birds. Golden Press, New York, pp 7-37.

Bi XX, Huang L, Jing MD, Zhang L, Feng PY and Wang AY (2012) The complete mitochondrial genome sequence of the black-capped capuchin (Cebus apella). Genet Mol Biol 35:545-552.

Bock WJ (1956) A generic review of the family Ardeidae (Aves). Am Mus Novit 1779:1-49.

Boore JL (1999) Animal mitochondrial genomes. Nucleic Acids Res 27:1767-1780.

Boore JL (2004) Complete mitochondrial genome sequence of Urechis caupo, a representative of the phylum Echiura. BMC Genomics 5:e67.

Braband A, Cameron SL, Podsiadlowski L, Daniels SR and Mayer G (2010) The mitochondrial genome of the onychophoran Opisthopatus cinctipes (Peripatopsidae) reflects the ancestral mitochondrial gene arrangement of Panarthropoda and Ecdysozoa. Mol Phylogenet Evol 57:285-292.

Campbell V and Lapointe FJ (2011) Retrieving a mitogenomic mammal tree using composite taxa. Mol Phylogenet Evol 58:149-156.

Cerasale DJ, Dor R, Winkler DW and Lovette IJ (2012) Phylogeny of the Tachycineta genus of New World swallows: Insights from complete mitochondrial genomes. Mol Phylogenet Evol 63:64-71.

Chang Q, Zhang BW, Jin H, Zhu LF and Zhou KY (2003) Phylogenetic relationships among 13 species of herons inferred from mitochondrial 12S rRNA gene sequences. Acta Zool Sin 49:205-210 (in Chinese with English abstract).

Chen W, Sun Z, Liu Y, Yue B and Liu S (2012) The complete mitochondrial genome of the large white-bellied rat, Niviventer excelsior (Rodentia, Muridae). Mitochondrial DNA 23:363-365.

Clements JF (2000) Birds of the World: A Checklist. 5th edition. Ibis Publishing Company Press, Vista, pp 18-25.

Cracraft J (1981) Toward a phylogenetic classification of the recent birds of the world (Class Aves). Auk 98:681-714.

Cracraft J, Barker FK, Braun MJ, Harshman J, Dyke GJ, Feinstein J, Stanley S, Cibois A, Schikler P, Beresford P, et al. (2004) Phylogenetic relationships among modern birds (Neornithes). Toward an avian tree of life. In: Cracraft $\mathrm{J}$ and
Donoghue MJ (eds) Assembling the Tree of Life. Oxford University Press, New York, pp 468-489.

Delarbre C, Rasmussen AS, Arnason U and Gachelin G (2001) The complete mitochondrial genome of the hagfish Myxine glutinosa: Unique features of the control region. J Mol Evol 53:634-641.

Delport W, Ferguson JW and Bloomer P (2002) Characterization and evolution of the mitochondrial DNA control region in hornbills (Bucerotifoormes). J Mol Evol 54:794-806.

Desjardins P and Morais R (1990) Sequence and gene organization of the chicken mitochondrial genome: A novel gene order in higher vertebrates. J Mol Biol 212:599-634.

Douzery E and Randi E (1997) The mitochondrial control region of Cervidae: Evolutionary patterns and phylogenetic content. Mol Biol Evol 14:1154-1166.

Dufresne C, Mignotte F and Gueride M (1996) The presence of tandem repeats and the initiation of replication in rabbit mitochondrial DNA. Eur J Biochem 235:593-600.

Fumagalli L, Taberlet P, Favre L and Hausser J (1996) Origin and evolution of homologous repeated sequences in the mitochondrial DNA control region of shrews. Mol Biol Evol 13:191-199.

Gao RR, Huang Y and Lei FM (2013) Sequencing and analysis of the complete mitochondrial genome of Remiz consobrinus. Zool Res 34:228-237 (in Chinese with English abstract).

Gardner PP, Wilm A and Washietl S (2005) A benchmark of multiple sequence alignment programs upon structural RNAs. Nucleic Acids Res 33:2433-2439.

Gentile G, Fabiani A, Marquez C, Snell HL, Snell HM, Tapia W and Sbordoni V (2009) An overlooked pink species of land iguana in the Galápagos. Proc Natl Acad Sci USA 106:507511.

Gibb GC, Kardailsky O, Kimball RT, Braun EL and Penny D (2007) Mitochondrial genomes and avian phylogeny: Complex characters and resolvability without explosive radiations. Mol Biol Evol 24:269-280.

Gibson A, Gowri-Shankar V, Higgs PG and Rattray M (2005) A comprehensive analysis of mammalian mitochondrial genome base composition and improved phylogenetic methods. Mol Biol Evol 22:251-264.

Gill FB (1990) Ornithology. WH Freeman Company Press, New York, pp 522-524.

Hackett SJ, Kimball RT, Reddy S, Bowie RC, Braun EL, Braun MJ, Chojnowski JL, Cox WA, Han KL, Harshman J, et al. (2008) A phylogenomic study of birds reveals their evolutionary history. Science 320:1763-1768.

Haring E, Kruckenhauser L, Gamauf A, Riesing MJ and Pinsker W (2001) The complete sequence of the mitochondrial genome of Buteo buteo (Aves, Accipitridae) indicates an early split in the phylogeny of raptors. Mol Biol Evol 18:18921904.

Härlid A, Janke A and Arnason U (1998) The complete mitochondrial genome of Rhea americana and early avian divergences. J Mol Evol 46:669-679.

Hedges SB and Sibley CG (1994) Molecules vs. morphology in avian evolution: The case of the "pelecaniform" birds. Proc Natl Acad Sci USA 91:9861-9865.

Howard R and Moore A (1980) A Complete Checklist of the Birds of the World. Oxford University Press, Oxford, pp 1-12. 
Ingman M, Kaessmann H, Paabo S and Gyllensten U (2000) Mitochondrial genome variation and the origin of modern humans. Nature 408:708-713.

Kahl MP (1972) A revision of the family Ciconiidae (Aves). J Zool 167:451-461.

Kan XZ, Li XF, Zhang LQ, Chen L, Qian CJ, Zhang XW and Wang L (2010) Characterization of the complete mitochondrial genome of the rock pigeon, Columba livia (Columbiformes, Columbidae). Genet Mol Res 9:1234-1249.

Kjer KM and Honeycut RL (2007) Site specific rates of mitochondrial genomes and the phylogeny of Eutheria. BMC Evol Biol 7:e8.

Krajewski C, Sipiorski JT and Anderson FE (2010) Complete mitochondrial genome sequences and the phylogeny of cranes (Gruiformes, Gruidae). Auk 127:440-452.

L'abbé D, Duhaime JF, Lang BF and Morais R (1991) The transcription of DNA in chicken mitochondria initiates from one major bidirectional promoter. J Biol Chem 266:1084410850.

McCracken KG and Sheldon FH (1997) Avian vocalizations and phylogenetic signal. Proc Natl Acad Sci USA 94:38333836.

Mindell DP, Sorenson MD and Dimcheff DE (1998) An extra nucleotide is not translated in mitochondrial ND3 of some birds and turtles. Mol Biol Evol 15:1568-1571.

Monroe BL and Sibley CG (1993) A World Checklist of Birds. Yale University Press, New Haven, 400 pp.

Moum T, Johansen S, Erikstad KE and Piatt JF (1994) Phylogeny and evolution of the auks (subfamily Alcinae) based on mitochondrial DNA sequences. Proc Natl Acad Sci USA 91:7912-7916.

Nesbø CL, Arab MO and Jakobsen KS (1998) Heteroplasmy, length and sequence variation in the mtDNA control regions of three percid fish species (Perca fluviatilis, Acerina cernua, Stizostedion lucioperca). Genetics 148:1907-1919.

Oh DJ, Oh BS, Jung MM and Jung YH (2010) Complete mitochondrial genome of three Branchiostegus (Perciformes, Malacanthidae) species: Genome description and phylogenetic considerations. Mitochondrial DNA 21:151-159.

Ojala D, Montoya J and Attardi G (1981) tRNA punctuation model of RNA processing in human mitochondria. Nature 290:470-474.

Pacheco MA, Battistuzzi FU, Lentino M, Aguilar RF, Kumar S and Escalante AA (2011) Evolution of modern birds revealed by mitogenomics: Timing the radiation and origin of major orders. Mol Biol Evol 28:1927-1942.

Payne RB and Risley CJ (1976) Systematics and evolutionary relationships among the herons (Ardeidae). Misc Publ Univ Mich Mus Zool 150:1-115.

Perna NT and Kocher TD (1995) Patterns of nucleotide composition at fourfold degenerate sites of animal mitochondrial genomes. J Mol Evol 41:353-358.

Peter JL (1931) Checklist of Birds of the World. Harvard University Press, Cambridge, 110 pp.

Posada D and Crandall KA (1998) Modeltest: Testing the model of DNA substitution. Bioinformatics 14:817-818.

Quinn TW and Wilson AC (1993) Sequence evolution in and around the mitochondrial control region in birds. J Mol Evol 37:417-425.

Rabosky DL and Matute DR (2013) Macroevolutionary speciation rates are decoupled from the evolution of intrinsic re- productive isolation in Drosophila and birds. Proc Natl Acad Sci USA 110:15354-15359.

Randi E and Lucchini V (1998) Organization and evolution of the mitochondrial DNA control region in the avian genus Alectoris. J Mol Evol 47:449-462.

Randi E, Lucchini V, Armijo-Prewitt T, Kimball RT, Braun EL and Ligon JD (2000) Mitochondrial DNA phylogeny and speciation in the tragopans. Auk 117:1003-1015.

Reyes A, Gissi C, Catzeflis F, Nevo E, Pesole G and Saccone C (2004) Congruent mammalian trees from mitochondrial and nuclear genes using Bayesian methods. Mol Biol Evol 21:397-403.

Ritchie PA and Lambert DM (2000) A repeat complex in the mitochondrial control region of Adelie penguins from Antarctica. Genome 43:613-618.

Roques S, Godoy JA, Negro JJ and Hiraldo F (2004) Organization and variation of the mitochondrial control region in two vulture species, Gypaetus barbatus and Neophron percnopterus. J Hered 95:332-337.

Russell RD and Beckenbach AT (2008) Recoding of translation in turtle mitochondrial genomes: Programmed frameshift mutations and evidence of a modified genetic code. J Mol Evol 67:682-695.

Saccone C, Pesole G and Sbisa E (1991) The main regulatory region of mammalian mitochondrial DNA: Structure-function model and evolutionary pattern. J Mol Evol 33:83-91.

Sato A, O'hUigin C, Figueroa F, Grant PR, Grant BR, Tichy H and Klein J (1999) Phylogeny of Darwin's finches as revealed by mtDNA sequences. Proc Natl Acad Sci USA 96:5101-5106.

Sbisà E, Tanzariello F, Reyes A, Pesole G and Saccone C (1997) Mammalian mitochondrial D-loop region structural analysis: Identification of new conserved sequences and their functional and evolutionary implications. Gene 205:125140.

Shadel GS and Clayton DA (1997) Mitochondrial DNA maintenance in vertebrates. Annu Rev Biochem 66:409-435.

Sheldon FH (1987) Rates of single-copy DNA evolution in herons. Mol Biol Evol 4:56-69.

Sheldon FH and Kinnarney M (1993) The effects of sequence removal on DNA-hybridization estimates of distance, phylogeny, and rates of evolution. Syst Biol 42:32-48.

Sheldon FH, McCracken KG and Stuebing KD (1995) Phylogenetic relationships of the zigzag heron (Zebrilus undulatus) and white-crested bittern (Tigriornis leucolophus) estimated by DNA-DNA hybridization. Auk 112:672-679.

Sheldon FH, Jones CE and McCracken KG (2000) Relative patterns and rates of evolution in heron nuclear and mitochondrial DNA. Mol Biol Evol 17:437-450.

Shen YY, Shi P, Sun YB and Zhang YP (2009) Relaxation of selective constraints on avian mitochondrial DNA following the degeneration of flight ability. Genome Res 19:17601765.

Shi Y, Shan X, Li J, Zhang X and Zhang H (2002) Sequence and organization of the complete mitochondrial genome of the Indian muntjac (Muntiacus muntjak). Acta Zool Sin 49:629-636.

Sibley CG and Monroe BL (1990) Distribution and Taxonomy of Birds of the World. Yale University Press, New Haven and London, pp 302-310. 
Sibley CG, Ahlquist JE and Monroe BL (1988) A classification of the living birds of the world based on DNA-DNA hybridization studies. Auk 105:409-423.

Song GH, Lin Q, Yue WB, Liu TF and Hu SN (2012) Sequence analysis of the complete mitochondrial genome and molecular evolution of Cricetulus griseus. Acta Lab Anim Sci Sin 20:70-75 (in Chinese with English abstract).

Sorenson MD, Ast JC, Dimcheff DE, Yuri T and Mindell DP (1999) Primers for a PCR-based approach to mitochondrial genome sequencing in birds and other vertebrates. Mol Phylogenet Evol 12:105-114.

Southern SO, Southern PJ and Dizon AE (1988) Molecular characterization of a cloned dolphin mitochondrial genome. J Mol Evol 28:32-42.

Sullivan J and Joyce P (2005) Model selection in phylogenetics. Annu Rev Ecol Evol Syst 36:445-466.

Suzuki H, Nunome M, Kinoshita G, Aplin KP, Vogel P, Kryukov AP, Jin ML, Han SH, Maryanto I, Tsuchiya K, et al. (2013) Evolutionary and dispersal history of Eurasian house mice Mus musculus clarified by more extensive geographic sampling of mitochondrial DNA. Heredity 111:375-390.

Taanman JW (1999) The mitochondrial genome: Structure, transcription, translation and replication. Biochim Biophys Acta 1410:103-123.

Tamura K, Peterson D, Peterson N, Stecher G, Nei M and Kumar S (2011) MEGA5: Molecular Evolutionary Genetics Analysis using maximum likelihood, evolutionary distance, and maximum parsimony methods. Mol Biol Evol 28:27312739.

Walberg MW and Clayton DA (1981) Sequence and properties of the human $\mathrm{KB}$ cell and mouse $\mathrm{L}$ cell D-loop regions of mitochondrial DNA. Nucleic Acids Res 9:5411-5421.

Wang C, Chen Q, Lu G, Xu J, Yang Q and Li S (2008) Complete mitochondrial genome of the grass carp (Ctenopharyngodon idella, Teleostei): Insight into its phylogenic position within Cyprinidae. Gene 424:96-101.

Wenink PW, Baker AJ and Tilanus MG (1994) Mitochondrial control-region sequences in two shorebird species, the Turnstone and the Dunlin, and their utility in population genetic studies. Mol Biol Evol 11:22-31.

Wolstenholme DR (1992) Animal mitochondrial DNA: Structure and evolution. Int Rev Cytol 141:173-216.

Wu X, Wang Y, Zhou K, Zhu W, Nie J and Wang C (2003) Complete mitochondrial DNA sequence of Chinese alligator, $\mathrm{Al}$ - ligator sinensis, and phylogeny of crocodiles. Chin Sci Bull 48:2050-2054.

Yamamoto Y, Murata K, Matsuda H, Hosoda T, Tamura K and Furuyama JI (2000) Determination of the complete nucleotide sequence and haplotypes in the D-loop region of the mitochondrial genome in the oriental white stork, Ciconia boyciana. Genes Genet Syst 75:25-32.

Yang R, Wu X, Yan P, Su X and Yang B (2010) Complete mitochondrial genome of Otis tarda (Gruiformes, Otididae) and phylogeny of Gruiformes inferred from mitochondrial DNA sequences. Mol Biol Rep 37:3057-3066.

Zhang P and Wake DB (2009) Higher-level salamander relationships and divergence dates inferred from complete mitochondrial genomes. Mol Phylogenet Evol 53:492-508.

Zhang L, Wang L, Gowda V, Wang M, Li X and Kan X (2012) The mitochondrial genome of the Cinnamon Bittern, Ixobrychus cinnamomeus (Pelecaniformes, Ardeidae): Sequence, structure and phylogenetic analysis. Mol Biol Rep 39:8315-8326.

Zheng ZX (1997) Fauna Sinica Aves. Vol. 1. Science Press, Beijing, pp 138-140.

Zheng GM (2002) A Checklist on the Classification and Distribution of the Birds of the WorId. Science Press, Beijing, 11 p.

Zhong D, Zhao GJ, Zhang ZS and Xu AL (2002) Advance in the entire balance and local unbalance of base distribution in genome. Hereditas 24:351-355.

Zwickl DJ and Hillis DM (2002) Increased taxon sampling greatly reduces phylogenetic error. Syst Biol 51:588-598.

\section{Supplementary Material}

The following online material is available for this article:

Table S1 - Species examined in this study.

Table S2 - Codon usage in the mitochondrial genome of E. garzetta.

Table S3 - Pairwise distances of 11 species inferred from the mitochondrial genome.

This material is available as part of the online article from http://www.scielo.br/gmb.

\section{Associate Editor: Houtan Noushmehr}

License information: This is an open-access article distributed under the terms of the Creative Commons Attribution License, which permits unrestricted use, distribution, and reproduction in any medium, provided the original work is properly cited. 